\title{
BMJ Open Sources of information used by patients prior to elective surgery: a scoping review
}

\author{
Alvin Atlas, ${ }^{\oplus 1,2}$ Steve Milanese, ${ }^{1}$ Karen Grimmer, ${ }^{1}$ Sarah Barras, ${ }^{3}$ \\ Jacqueline H Stephens ${ }^{\oplus 4}$
}

To cite: Atlas A, Milanese $\mathrm{S}$, Grimmer K, et al. Sources of information used by patients prior to elective surgery: a scoping review. BMJ Open 2019;9:e023080. doi:10.1136/ bmjopen-2018-023080

- Prepublication history and additional material for this paper are available online. To view these files, please visit the journal online (http://dx.doi. org/10.1136/bmjopen-2018023080).

Received 3 September 2018 Revised 7 June 2019 Accepted 7 June 2019

Check for updates

(c) Author(s) (or their employer(s)) 2019. Re-use permitted under CC BY-NC. No commercial re-use. See rights and permissions. Published by BMJ.

${ }^{1}$ International Centre for Allied Health Evidence, School of Health Sciences, University of South Australia Division of Health Sciences, Adelaide, South Australia, Australia

${ }^{2}$ Health Market Quality Research, Capital Markets CRC Ltd, Sydney, New South Wales, Australia

${ }^{3}$ Australian Health Service Alliance, Camberwell, Victoria, Australia

${ }^{4}$ Centre for Population Health Research, University of South Australia Division of Health Sciences, Adelaide, South Australia, Australia

Correspondence to Alvin Atlas;

Alvin.Atlas@unisa.edu.au

\section{ABSTRACT}

Objective To describe the range and nature of available research regarding sources of information that patients access to inform their decisions about elective surgery. Design Scoping review.

Data sources Peer-reviewed studies published until February 2019 from the six scientific literature databases were searched and included in the study: Medline, PubMed, CINAHL, Academic Search Premier, EMBASE and SCOPUS. Web searches for grey literature were conducted in Google, South Australia Department of Health, Commonwealth Department of Health (Australia) and My Aged Care from the Department of Social Services (Australia).

Eligibility criteria Studies with a focus on elective surgery information sources oriented to patients were eligible for inclusion. Only studies written in English were sought and no publication date or study restrictions were applied.

Data extraction and synthesis Included literature was described by National Health and Medical Council hierarchy of evidence, and data were extracted on country and year of publication, type of literature, who provided it and any information on end users. Information sources were categorised by type and how information was presented.

Results A pool of 1039 articles was reduced to 26 after screening for duplicates and non-relevant studies. Face-to-face exchanges were the most likely source of information prior to elective surgery (59.3\%), printed information (55.6\%) followed by e-learning (51.9\%) and multimedia (14.8\%). The face-to-face category included information provided by the physician/general practitioners/specialists, and family and friends.

Printed information included brochures and pamphlets, e-learning consisted of internet sites or videos and the use of multimedia included different mixed media format.

Conclusion There is considerable variability regarding the types of information patients use in their decision to undergo elective surgery. The most common source of health information (face-to-face interaction with medical personnel) raises the question that the information provided could be incomplete and/or biased, and dependent on what their health provider knew or chose to tell them.

\section{Strengths and limitations of this study}

- The scoping review was conducted to identify available evidence on the health information used by patients that could inform future research and healthcare practices.

This scoping review represents a diverse sample of elective surgery procedures.

- There is limited research on patient decision making for elective surgery procedures.

- Quality assessment of the included studies will not be conducted as this scoping review aims to provide a snapshot of the different sources of information used by patients prior to elective surgery by being inclusive of all types of information currently available.

\section{INTRODUCTION}

Elective surgery is a term used to describe non-emergency surgery which is medically necessary, but which can be delayed for at least 24 hours. ${ }^{1}$ There has been an increasing demand for elective surgery in Australia over the past decade, however, the capacity of health systems to respond to has been limited by funding and workforce availability. ${ }^{2}$

In public hospitals, there are generally constraints on resources (such as workforce training, workforce availability, operating theatres and beds). ${ }^{3}$ Access to elective surgery is rationed through the use of waiting lists in which patients are assigned to urgency categories. ${ }^{4}$ Elective surgery in public hospitals can be provided for people who have inadequate or no private health insurance, and who rely on Medicare funding for their healthcare. Medicare is the Australian universal public health insurance which pays standard fees for medical and hospital care for all Australian citizens and permanent residents. ${ }^{5}$ In private hospitals, when privately funded patients register for elective surgery, waiting lists rarely exist because patients and/or their insurer(s) are paying the costs of surgery. 
Data from the Australian Institute of Health and Welfare indicate that in 2014-2015, public hospitals admitted approximately 698000 patients from elective surgery waiting lists. ${ }^{6}$ Between 2010 and 2011 and 2014 and 2015, elective surgery admissions in public hospitals increased by $1.3 \%$. Elective surgery admissions to private hospitals increased by an average of 3\% per year between 2010 and 2011 and 2014 and 2015. This translates to an increase in private hospital elective surgery admissions from 1279501 (2010-2011) to 1438722 (2014-2015). ${ }^{7}$

Little is known about the impact of surgical waiting lists on patients, their families, workplaces or society. There is little consistency on how waiting time is defined and monitored, and little is understood on the social, financial and health impact of waiting on patients. ${ }^{89}$ Moreover, there is rarely a 'best choice' for the management of many health conditions. ${ }^{10}$ Over $50 \%$ patients placed on an orthopaedic surgical waiting list of a large tertiary hospital were managed effectively without surgery, by early physiotherapy triage, education about their condition and offering a range of conservative treatment options. ${ }^{11}$ Ensuring that patients can make informed choices at the time of referral to an elective surgery waiting list might assist patients to engage more actively in treatment decisions. ${ }^{12}$

To be able to make the best decision regarding treatment options, patients require an adequate level of health literacy and comprehensive information sources. This should include information about their condition and all possible treatment alternatives, risks and benefits. ${ }^{13}$ Health literacy relates to patients and their families having the skills and supports to make considered decisions about their best healthcare options. ${ }^{14}$ Compared with adequate health literacy, poor health literacy has been associated with increased rates of hospitalisations and greater use of emergency care, poorer ability to demonstrate taking medications appropriately, poorer ability to interpret labels and health messages, poorer knowledge among patients regarding their health conditions, poorer overall health status and higher risk of death among older people. ${ }^{1516}$

Individuals' ability to access, understand and use information about their condition will influence the decisions they make, and actions they take, about treatment. ${ }^{13} 17$ To support their health literacy, patients require readily accessible, clear, focused, usable and evidence-based information about their health condition, the available healthcare choices, and costs, risks and likely outcomes from each. ${ }^{18}$

However, little is known about how, why and where patients access health information. ${ }^{19} 20$ In order to improve patient health literacy, more needs to be known regarding whether patients are utilising any of the information available to them in making health decisions regarding elective surgery, or what information sources are most readily accessed and valued. It has been suggested that despite the explosion of available information, patients may still receive care that is based more on their provider's habits and choices, than their own preferences. ${ }^{21}$

Access to health information is essential in the shared decision-making (SDM) process between the patients and healthcare practitioners. SDM involves collaboration between the patient and the practitioner to discuss treatment options, ensures that the patient is adequately informed, and decides on the care options taking into consideration the patient's principles and preferences. ${ }^{22}$ Patient participation in SDM with their health practitioner is higher when they know their treatment, screening or diagnostic procedure options. ${ }^{23}$

This scoping review was undertaken with the aim of describing the range and nature of available research concerning the sources of information that patients access to inform their choices about elective surgery, and how this information is used in their decision making.

\section{METHODS}

The methodology was based on the framework outlined by Arksey and O'Malley, ${ }^{24}$ and the recommendations made by Levac et al. ${ }^{25}$ Scoping review phases comprised defining the research question, searching for relevant studies, selecting the studies relevant to the scoping question, charting the data, and collating, summarising and reporting the results. The only review phase which was not undertaken was the optional consultation phase, as this was not relevant to the review purpose.

\section{Defining the research question}

This scoping review was guided by the research question: 'What are the sources of information that patients use to inform their decision to undergo elective surgery?'

\section{Identifying relevant studies}

The liaison health librarian at the University of South Australia independently conducted the literature searches in April 2016, and these were checked again in February 2019. Only studies written in English were sought, and no publication date or study design restrictions were applied. Six scientific databases were searched: Medline, PubMed, CINAHL, Academic Search Premier, EMBASE and SCOPUS. Search queries were tailored to the specific requirements of each database (see the online supplementary file 1 ).

A grey literature search was undertaken to identify seminal documents regarding health literacy and patient choice that may have been developed for purposes other than scientific peer-reviewed publications. Web searches for the grey literature were conducted via Google (http:/ / www.google.com); SA Department of Health (http:// www.sahealth.sa.gov.au); Commonwealth Department of Health (http://www.health.gov.au); and the Department of Social Services My Aged Care (http://www.myagedcare.gov.au).

The search terms used included Medical Subject Headings, and words and phrases identified from 
the preliminary reading. The reference lists of included studies and grey literature were also manually searched to identify additional papers not captured in the search. The new literature was collated using a snowball technique where new literature was counted once only.

\section{Selecting the literature}

Studies were eligible for inclusion if they were scientific papers focused on elective surgery and patients' health literacy and concerned with the sources of information influencing patients' decisions to undergo elective surgery. To standardise screening decisions, the inclusion criteria were developed into a questionnaire and used for a two-staged screening process to determine the relevance of the literature.

For first stage screening, the title and abstract of citations were reviewed independently by two reviewers (AA and SM). Reviewers were not masked to the author or journal name. Disagreements whether or not literature should be included for full review were resolved through discussion until consensus is reached. Reviewers met throughout the screening process to resolve conflicts and discuss any uncertainties related to study selection. ${ }^{25}$

For second stage screening, all citations deemed potentially relevant after first stage screening were procured in full text. For articles that could not be obtained through institutional holdings available to the authors, attempts were made to contact the author or journal for assistance in procuring the article. Second stage screening used the same approach as the first stage screening. The same reviewers screened the full texts believed to be relevant to the search question, using the same questionnaire. Disagreements were resolved through discussion.

\section{Data extraction}

To evaluate and present the findings, as many sources of information as possible were extracted from the included articles. As some articles included multiple sources of information, the overall totals in data categories often exceeded the number of studies. Data were extracted using standard forms and entered into Micrososft Excel tables by one reviewer (AA) and synthesised in summary format. Extracted data included study and population characteristics such as authors, year of publication, the study sample, the country in which the study took place, the study design and the study methodology used, the sources of information used prior to elective surgery and the type of elective surgery done. The study design was determined using the National Health and Medical Research Council hierarchy of evidence. ${ }^{26}$ The type of elective surgery was determined based on the surgical specialty as defined by the SA Health- Government of South Australia. ${ }^{27}$ The tables were independently checked for accuracy by a second reviewer (SM), who randomly selected five research studies and checked the extracted data against the full-text study. Disagreements were resolved through discussion. The information extracted that helped answer the research questions was discussed during meetings to generate an overall perspective on the factors emerging from the literature.

\section{Data summary and synthesis}

The completed data extraction files were exported into STATA V. $12^{28}$ for descriptive analyses such as frequency and percentage to summarise available data. ${ }^{24}$ An essential step in the data summary process was a regular author group discussion of the nuances in the extracted data to establish overall perspectives on the sources of information patients were reported to use prior to elective surgery. The information in the spreadsheet was colourcoded according to the different sources of information used, in order to assist with organising the reporting of the scoping review findings. Studies were grouped according to the source of information used prior to elective surgery, the study design and the type of elective surgery done.

\section{Patient and public involvement}

The scoping review was done to describe the available research about the sources of information that patients use prior to elective surgery. Patients and the public were not involved in any stage of the scoping review process.

\section{RESULTS}

\section{Search findings}

The search yielded 1039 potentially relevant citations. After removal of duplicates and irrelevant papers, 865 citations met the eligibility criteria based on title and abstract. These were obtained and full-text screened, with 26 studies included in the analysis. The CONSORT diagram describing the article inclusion process is outlined in figure 1.

\section{Study design and sample}

The general characteristics of the included literature are reported in table 1 . Of the 26 included studies, $69.2 \%$ $(18 / 26)$ were published after 2009 , with only one study coming from a developing country. The majority of studies investigating sources of information prior to elective surgery occurred in the UK, USA and Australia $(15 / 26)$. A complete description of the included studies can be found in the online supplementary file 2 .

Considering study design, 19 studies were quantitative, with cross-sectional studies the most common design. Five qualitative studies used phenomenological and non-participant observation, and one study used a mixed method research design. Ten studies involved patients who had undergone orthopaedic surgery (hip and knee arthroplasty, hip, knee and shoulder arthroscopy, back surgery and anterior cruciate ligament reconstruction). The remaining studies involved patients who had general surgery, ear, nose and throat (ENT), urological, thoracic, plastic or cancer-related surgery.

Sources of information based on the type of elective surgery This review found that patients accessed a range of information sources during their decision-making process 

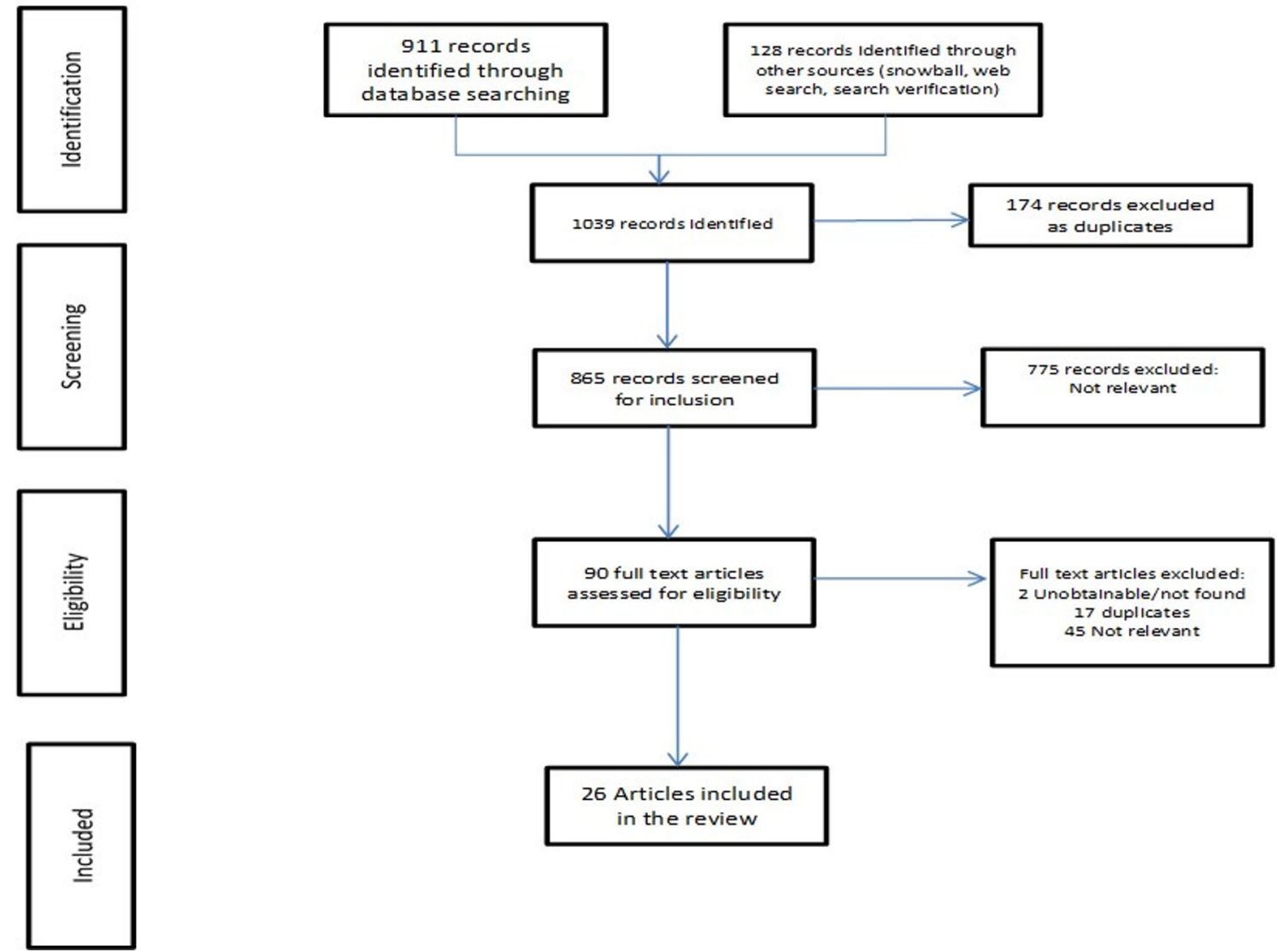

Figure 1 Search strategy and results.

prior to undergoing elective surgery. The type of information used by patients is presented in table 2 .

\section{General surgery}

In five studies, in which the elective surgery type was not specified, the use of the internet, reliance on general practitioner (GP) or specialist-directed decisions, and influence of the family were the reported as the most common sources of information prior to elective surgery. ${ }^{19}$ 29-32

\section{Orthopaedic surgery}

Hip, knee, back and shoulder orthopaedic surgeries were reported in the largest percentage of included studies $(8 / 27(30 \%))$. To facilitate SDM processes, sources of information varied, such as the use of decision aids ${ }^{33}$; multimedia tools ${ }^{34} 35$; interactive videos and booklets ${ }^{36} 37$; online educational resources ${ }^{38}$; the internet ${ }^{38-40}$; verbal education $^{41}$; written educational material ${ }^{41}$; physician/ surgeon ${ }^{124-44}$; and family and friends. ${ }^{43} 44$

\section{ENT surgery}

There was one cross-sectional study on the information accessed by patients undergoing elective ENT surgery. Information sources included information supplied by the GP, specialist information, from preadmission clinics, self-obtained information from internet and friends, and information from the surgery consent form. Information from the preadmission clinic $(8 / 10)$ and outpatient consultation $(7.5 / 10)$ was perceived and rated as having the highest quality. ${ }^{45}$

\section{Bariatric/cosmetic/plastic surgery}

There are three studies about cosmetic/bariatric surgery. ${ }^{46-48}$ The commonly used sources of information were video-based decision aids, ${ }^{46}$ educational booklets, ${ }^{46}$ family and friends, and media exposure. ${ }^{47}$ The use of high-quality, video-based decision aids were shown to significantly improve knowledge of the risk and benefits before bariatric surgery. Patients were randomly assigned to review either a video-based decision aid or an educational booklet on bariatric surgery. Changes in patient decision quality were assessed using bariatric-specific measures of knowledge, values and treatment preference after 3 months. Thus, it appears that decision aids may be an important adjunct to bariatric treatment decisions in the future. Information about the experiences of family and friends who had elective surgery increased the likelihood of women undergoing cosmetic surgery. This is due to the increased amount of information that the patient has access to, to clarify misinformation that may cause anxiety and indecisiveness. ${ }^{49}$ Media exposure did not influence the likelihood of cosmetic surgery for either sex. ${ }^{49}$

\section{Other types of the elective surgery}

Four papers reported health literature use for other types of elective surgery, which were colorectal surgery, 
Table 1 General characteristics of included studies $(\mathrm{N}=26)$

\begin{tabular}{|c|c|c|}
\hline Characteristics & Number, $n$ & Percentage \\
\hline \multicolumn{3}{|l|}{ Publication year } \\
\hline 2000-2004 & 4 & 15.4 \\
\hline 2005-2009 & 4 & 15.4 \\
\hline 2010-2015 & 18 & 69.2 \\
\hline \multicolumn{3}{|l|}{ Location of the study } \\
\hline Australia & 5 & 19.2 \\
\hline Canada & 2 & 7.7 \\
\hline Finland & 1 & 3.8 \\
\hline Iran & 1 & 3.8 \\
\hline Netherlands & 1 & 3.8 \\
\hline New Zealand & 1 & 3.8 \\
\hline Sweden & 1 & 3.8 \\
\hline Switzerland & 1 & 3.8 \\
\hline Taiwan & 3 & 11.5 \\
\hline UK & 6 & 23.1 \\
\hline USA & 4 & 15.4 \\
\hline \multicolumn{3}{|l|}{ Study design } \\
\hline Cross-sectional & 11 & 42.3 \\
\hline Randomised controlled trial & 8 & 30.8 \\
\hline Cohort & 1 & 3.8 \\
\hline Phenomenological & 4 & 15.4 \\
\hline Observational & 1 & 3.8 \\
\hline Mixed method & 1 & 3.8 \\
\hline \multicolumn{3}{|l|}{ Elective surgery specialty* } \\
\hline General surgery & 10 & 37 \\
\hline Ophthalmology & 0 & 0 \\
\hline Neurosurgery & 0 & 0 \\
\hline Orthopaedics & 10 & 37 \\
\hline ENT & 1 & 3.7 \\
\hline Urology & 1 & 3.7 \\
\hline Gynaecology & 0 & 0 \\
\hline $\begin{array}{l}\text { Bariatric/cosmetic/plastic } \\
\text { surgery }\end{array}$ & 3 & 7.4 \\
\hline Thoracic surgery & 1 & 3.7 \\
\hline Craniofacial surgery & 0 & 0 \\
\hline Cancer-related surgery & 1 & 3.7 \\
\hline
\end{tabular}

*There were no studies reporting ophthalmology, neurosurgery, gynaecology, thoracic surgery or craniofacial surgery. One study included urological and general surgery. ENT, ear, neck and throat.

coronary artery bypass graft/mitral valve replacements, and hernia repair and cholecystectomy. Video education was introduced as an adjunct to verbal information to prepare patients psychologically for elective colorectal surgery. The supplemental video education with oral and printed information was concluded to be better in preparing patients for surgery and in helping to improve their short-term outcomes in the enhanced recovery programme. ${ }^{50}$ Of the patients, $88 \%$ rated the video information provided as adequate with $28 \%$ finding the video very helpful and more useful than other forms of patient information.

Another study provided cardiac surgery patients with a 24-page booklet to educate them on their operation, what to expect postsurgery, activity restrictions and recommendations for a safe discharge home. A survey was designed to elicit responses regarding patients' experiences of both preoperative written information received and postoperative services they received from occupational therapy while in acute care. Overall, patients were satisfied with the preoperative cardiac surgery education provided in the written format booklet and believed that this adequately prepared them for surgery. ${ }^{51}$

A third study established the proportion of patients undergoing elective hernia repair or cholecystectomy, who searched the internet for information about their operations, in addition to receiving counselling and standard information at preadmission clinics. ${ }^{52}$ Of the patients, $59 \%$ had internet access with $79 \%$ of those with access searching for further information about their procedure on the internet. Patients who completed a questionnaire on the morning of their operation regarding their preparation for the operation in terms of health knowledge rated the information they had received as 'very good' or 'good'. However, there was considerable variability in the standard information regarding surgical treatment options and surgical complications, and this resulted in $26 \%$ of patients feeling confused or worried. ${ }^{53}$ Printed education materials used on patients with colorectal cancer undergoing elective surgery were rated as adequate by patients but did not satisfy their demands or information needs. ${ }^{53}$ In fact, there were demands for more information tailored to the level of patients' health literacy and information needs. Printed education materials adapted to individual patient needs have been shown to improve patient recovery during the first year following colorectal cancer surgery. ${ }^{54}$

A study involving patients who had non-emergency surgeries of herniorrhaphy, cholecystectomy and nephrectomy showed that face-to-face verbal education and using pamphlets are both valuable in improving the readiness to have surgery. ${ }^{55}$

\section{Information sources categorisation}

The different sources of information identified in this review were further categorised, based on the source of health information, as shown in table 3 . The total number of sources of information is greater than the number of studies as some studies reported multiple sources of information used. 'Hard copy' includes pamphlets, booklets, brochures, written educational and information materials, and newspapers. Internet, patient education and interactive videos, and online education were categorised under E-learning. Face-to-face includes GP/physician and specialist, healthcare provider, social networks such as family, friends, acquaintances and hospital employees. Combinations of the different sources of information 
Table 2 Sources of information used based on elective surgery specialty

\begin{tabular}{|c|c|}
\hline Specialty & Information used prior to elective surgery \\
\hline General surgery & Internet, family, physician, family and friends, video, books, magazines, newspapers, leaflets \\
\hline Orthopaedics & $\begin{array}{l}\text { Physician directed, family and friends, hospitals and healthcare providers, internet, multimedia, } \\
\text { printed educational material, online education resource }\end{array}$ \\
\hline ENT & Physician (general practitioner and specialist), internet, friends, \\
\hline $\begin{array}{l}\text { Bariatric/cosmetic/plastic } \\
\text { Surgery }\end{array}$ & Family and friends, media exposure, educational booklet, video-based decision aid \\
\hline Cardiothoracic & Printed education materials \\
\hline Urology & Physician, printed education materials \\
\hline
\end{tabular}

ENT, ear, neck and throat.

such as multimedia tools or decision aids were categorised as 'mixed'.

Of the 16 studies which reported face-to-face interaction as the commonly used information exchanges, consultation with the physician was the most common source of information for patients, which was believed to promote SDM. SDM offers a process which can help a physician and patient move beyond passive informed consent to a more collaborative, patient-centred experience. It reduces conflict and improves the quality of the decision for patients who are making choices about elective surgery. ${ }^{12}$ One of the most important predictors of willingness to undergo elective surgery such as orthopaedic procedures is having previously discussed this procedure with a physician, emphasising the importance of the patient-physician interaction in patients' decision making regarding surgery and medical care. ${ }^{56}{ }^{57} \mathrm{In}$ the study by Ankuda et $a l,{ }^{58}$ although most patients $(55 \%)$ reported SDM with their surgeon, $36 \%$ reported patientdriven decision making and another $9 \%$ reported physician-driven decision making. Patients saw clinicians as occupying expert roles and they deferred to clinicians' expertise. There was also evidence that patients modified their behaviour within consultations to complement that of clinicians. ${ }^{42}$

Opinions and experiences of family and friends are reported to have significant influence over patients deciding to undergo elective surgery. ${ }^{29}$ This appears particularly relevant to cosmetic surgery. There is an increase in the number of people considering elective cosmetic surgery, possibly due to increased media attention and that many people personally know someone who had elective cosmetic surgery. ${ }^{50}$ The experiences and information from family and friends were considered as reliable and accurate resulting in greater acceptance of the procedure and increasing likelihood of people undergoing cosmetic surgery in the future.$^{59}$ This societal trend may increase knowledge of, and familiarity with, cosmetic surgery and patients undergoing cosmetic surgery. ${ }^{5160}$

Printed educational materials such as pamphlets and booklets were the most common hard resource among the 15 studies that reported hard copy as an information source. Under e-learning, searching for health information using the internet is the most common. Studies suggest that $50 \%-80 \%$ of adults with internet access use it for healthcare purposes. ${ }^{61}$

\section{DISCUSSION}

This scoping review provides the first synthesis of systematically sourced information that describes the types and ways, in which people access information to inform their decisions about elective surgery. The body of evidence consists of 26 studies, including eight randomised controlled trials, with the remainder lower level hierarchy observational studies. These described a range of evidence sources which patients have been reported to use, to inform their choices for elective surgery for a range of health conditions. Although this review highlights research interest in the developed world regarding this topic, only one study was included from developing countries.

The most common source of information was doctors, specifically hospital consultants/specialists and general medical practitioners. ${ }^{58}$ This review found that patients were generally satisfied with the information they received from their GP. They saw doctors as occupying expert roles, thus they deferred to their expertise. ${ }^{43}$ However, some studies reported that patients later stated that they had not raised disagreements or misgivings with doctors (particularly surgeons), and some expressed surprise about the decisions that were made on their behalf. ${ }^{62}$ Patients might modify their behaviour in order to better match it to the styles of their medical practitioners, and that this may manifest itself as deference to the doctor's expertise during consultations. ${ }^{63}$ This raises the question of the potential power imbalance between medical practitioners and patients, which may also be sustained by differential awareness of the importance of role and communication in medical decision making. ${ }^{42}$

The studies appeared to report an increasing trend wherein patients relied on health information coming from outside the healthcare environment and their medical practitioners. ${ }^{45} 6465$ Doctors should not be 
Table 3 Source of health literature used by consumers

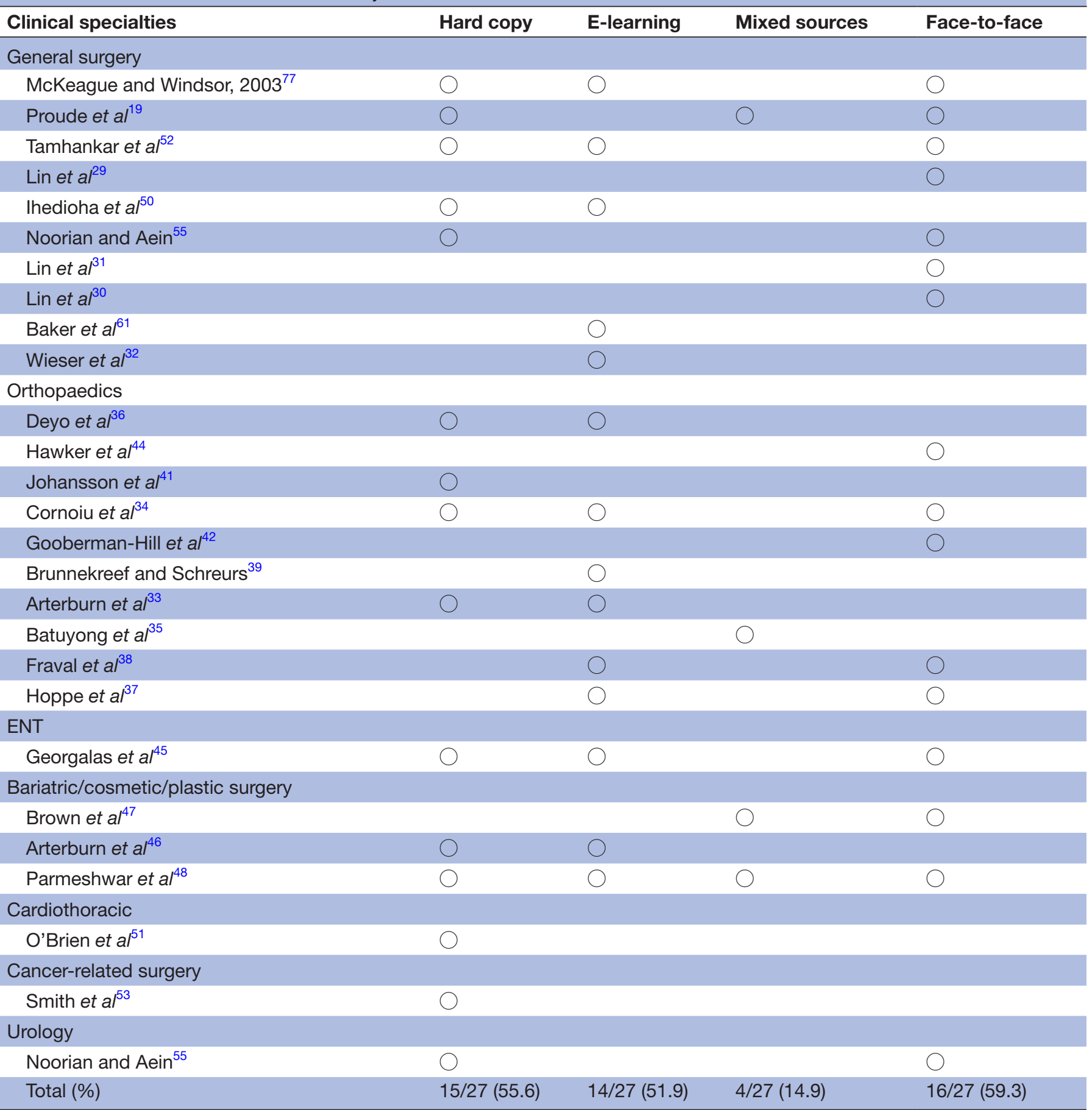

ENT, ear, nose and throat.

threatened by this, and instead, they must acknowledge that guiding patients to other sources (self-help groups, internet sites, organisations) may be as important as time actually spent talking to them. Recognising this creates a common language with the patient and can help to bypass any feelings of antagonism. ${ }^{45}$

The role of family and friends cannot be overestimated. As this review found, they have critical influences on patients' health decision making. Family members played an important role in medical decision making for elective surgery, which could enhance or restrict individual patient autonomy during the decision making process. Family members may include spouse, parents or adult children. Patients were aware that their suffering affected both themselves and their family, and they considered the primacy of the family in their treatment decisions, including compromising or agreeing to surgery to allay family anxiety or concerns. ${ }^{58}$ Family was identified in this review as informant information brokers, where family members can become even more informed than patients. 
Thus, the family can provide an important communication channel between medical practitioners and patients particularly if decision making is complex. ${ }^{58}{ }^{66}$ Family members can also act as patient advocates by defending the interests of the patient during consultations and in the surgery decision-making process. Thereby, patients and their families can act constructively as co-agents in healthcare decision making and in ongoing interactions with medical professionals. ${ }^{58}$

The use of the internet as a source of health information is rapidly growing. ${ }^{196768}$ There were approximately 13.3 million internet subscribers in Australia at the end of June 2016. Thus, the number of households with access to the internet at home has steadily increased in the recent past, reaching 7.7 million in 2014-2015, and representing an increase of $3 \%$ from $83 \%$ in 2012-2013. ${ }^{69}$ Patients who were more likely to use the internet were younger, better educated and employed. ${ }^{19}$ According to a study by Wong et al, out of the 2944 study participants, $28.1 \%$ had sought health information online and $17.1 \%$ had obtained information related to problems managed by the GP at that visit. The use of internet and online health information was inversely associated with age. ${ }^{70}$ The most socioeconomically advantaged patients were significantly more likely to have obtained health information online. Disseminating health and medical information on the internet can improve knowledge transfer from health professionals to the population, and help patients to maintain and improve their health. ${ }^{71}$ However, this is a largely unregulated source of information, thus there are reasonable concerns on the quality of health information available on the internet. ${ }^{72}$ Information provided on the internet can be incomplete or based on insufficient scientific evidence, and moreover, the internet information can be overwhelming, conflicting and confusing. ${ }^{69} 73$

Other sources of information can be categorised as decision aids. These typically include brochures or pamphlets, videos or websites that can present factual information about a condition, authored by reputable sources. These information sources often present health information in plain, easy-to-understand language; describe alternative treatments; and provide information about risks and benefits associated with treatment options. Studies have shown that decision aids consistently increase patients' knowledge; improve treatment expectations; increase active participation in decision making; reduce decisional conflict or uncertainty about the appropriate course of action; decrease the proportion of people remaining undecided about treatment; and help patients reach decisions that are closely aligned with their stated values. ${ }^{74}$ The studies also suggest that the use of decision aids is associated with $25 \%$ fewer patients electing to have surgery. ${ }^{10}$ The consistent use of patient decision aids may reduce the rates of elective surgery and lower healthcare costs. ${ }^{33}$ The use of multimedia aids (computer-based, patient-controlled interactive educational tool) has been reported to have a significant effect on knowledge transfer and patient learning. ${ }^{38}$ These aids are an adjunct to physician-patient encounters and not a substitute for them. ${ }^{75}$ The use of multimedia programmes developed specifically for preadmission use provides patients with opportunities to access detailed, high-quality information regarding their upcoming surgery, combined with pertinent details of their hospitalisation and treating physician. Multimedia tools assist patients to determine exactly how much, and the depth of, information they receive. Information about the development of the disease and alternative therapies can be presented in detail; in the programme, patient and the patients have access to accurate information regarding alternatives, self-help groups and even comments from other patients. The use of the multimedia tool can reduce the communication gap between doctor and patient by giving patients the chance to educate themselves about the upcoming operation. ${ }^{35} 75$ In the presence of multiple sources of health information, the challenge is how it can be tailored to deliver information specific to patients' needs.

A limitation of this review is the potential bias introduced by the inclusion of studies written in English. This will exclude additional information that might be generated from non-English studies. The timing of information sources and the outcomes measured in each study were not included in the analysis. Reviews involving these important variables should be undertaken in the future.

\section{CONCLUSION}

This review indicated considerable variability in the types of information patients use in their decision to undergo elective surgery. Face-to-face interaction remains the most common source of patient health information prior to making choices about elective surgery. This can come from consultation with GP/specialist, and information from family and friends. Many patients consider the GP/ specialist as experts and family/friends as advocates on their behalf. Other sources of health information such as the use of multimedia and decision aids have a positive effect on knowledge translation to the patient. This provides relevant evidence-based information to facilitate SDM processes between patient and doctors.

Contributors AA, SM, KG, SB and JHS: involved in the conception and design of the study; contributed to the data analysis and synthesis, drafting and revision of the article and the final approval of the version for publication. AA and SM: performed the screening of the studies included in the review.

Funding This work was conducted as part of $\mathrm{PhD}$ candidature funded by a scholarship grant by the Capital Markets Cooperative Research Centre and the Australian Health Service Alliance.

Competing interests None declared.

Provenance and peer review Not commissioned; externally peer reviewed.

Data sharing statement Requests for access to data should be addressed to the corresponding author.

Open access This is an open access article distributed in accordance with the Creative Commons Attribution Non Commercial (CC BY-NC 4.0) license, which permits others to distribute, remix, adapt, build upon this work non-commercially, and license their derivative works on different terms, provided the original work is 
properly cited, appropriate credit is given, any changes made indicated, and the use is non-commercial. See: http://creativecommons.org/licenses/by-nc/4.0/.

\section{REFERENCES}

1. Department of Health-Government of Western Australia. Healthy WA: healthy information for Western Australians. Western Australia: Department of Health, 2006. http://healthywa.wa.gov.au/Articles/A E/Elective-surgery. (cited 10 Feb 2017).

2. Curtis AJ, Wolfe R, Russell CO, et al. Determining priority for joint replacement: comparing the views of orthopaedic surgeons and other professionals. Med J Aust 2011;195:699-702.

3. Willis EM, Reynolds L, Keleher H. Understanding the Australian Health Care system. 2nd edn. Chatswood NSW: Elsevier Australia, 2012:32.

4. Burgess K, Berryman L, Mclntyre J, et al. Australian hospital statistics 2013-14: elective surgery waiting times Health services series no. 56. Canberra, ACT: Australian Institute of Health and Welfare Health, 2014:62.

5. Healy J, Sharman E, Lokuge B. Australia: Health systems review Report no.5. Copenhagen, Denmark: WHO Regional office for Europe European Observatory on Health Care Systems, 2006:158.

6. Australian Institute of Health and Welfare. Elective surgery waiting times 2014-15: Australian hospital statistics. Health services series no. 64. Cat. no. HSE 166. Canberra: AlHW, 2015.

7. Australian Institute of Health and Welfare. Admitted patient care 2014-15: Australian hospital statistics. Health services series no. 68. Cat. no. HSE 172. Canberra: AlHW, 2016.

8. Oudhoff JP, Timmermans DR, Knol DL, et al. Waiting for elective general surgery: impact on health related quality of life and psychosocial consequences. BMC Public Health 2007;7:164

9. Morris J, Twizeyemaria A, Pillen $\mathrm{H}$, et al. What happens when patients with an orthopaedic complaint 'wait'? Setting the scene in one Australian tertiary hospital. Asia Pac J Public Health 2017; 12:34-41.

10. Stacey $\mathrm{D}$, Légaré $\mathrm{F}$, Lewis $\mathrm{K}$, et al. Decision aids for people facing health treatment or screening decisions. Cochrane Database Syst Rev 2017;4(Issue 4):CD001431.

11. Morris J, Grimmer-Somers K, Kumar S, et al. Effectiveness of a physiotherapy-initiated telephone triage of orthopedic waitlist patients. Patient Relat Outcome Meas 2011;2:151-9.

12. Page AE. Safety in surgery: the role of shared decision-making. Patient Saf Surg 2015;9:24.

13. Australian Commission on Safety and Quality in Health Care. Consumers, the health system and health literacy: Taking action to improve safety and quality. Consultation Paper. Sydney: ACSQHC, 2013.

14. Weinstein JN, Clay K, Morgan TS. Informed patient choice: patient centred valuing of surgical risks and benefits. Health Aff 2007;26:726-30.

15. Berkman ND, Sheridan SL, Donahue KE, et al. Health Literacy Interventions and Outcomes: an Updated Systematic Review Evidence Report/Technology Assessment No. 199: RTI InternationalUniversity of North Carolina Evidence-based Practice Center, 2011:941.

16. Bush R, Boyle F, Ostini R, et al. Advancing Health Literacy through Primary Health Care Systems. Canberra: Australian Primary Health Care Research Institute, 2010:52.

17. Davis RE, Jacklin R, Sevdalis N, et al. Patient involvement in patient safety: what factors influence patient participation and engagement? Health Expect 2007;10:259-67.

18. Australian Commission on Safety and Quality in Health Care. Health literacy: Taking action to improve safety and quality. Sydney: ACSQHC, 2014.

19. Proude EM, Shourie S, Conigrave KM, et al. Do elective surgery patients use the internet to look for information about their condition? ANZ J Surg 2004;74:304-7.

20. Cutilli CC. Seeking health information: what sources do your patients use? Orthop Nurs 2010;29:214-9.

21. FamiliesUSA:The voice for health consumers. Shared decision making: engaging patients to improve health care. $2013 \mathrm{http}: / /$ familiesusa.org/product/shared-decision-making-engaging-patientsimprove-health-care (Accessed 20 Dec 2017).

22. Lizarondo L, Pham C, Aromataris E, et al. Strategies for implementing shared decision making in elective surgery by healthcare practitioners: a systematic review protocol. JBI Database System Rev Implement Rep 2016;14:100-8.

23. Hoffmann TC, Légaré F, Simmons MB, et al. Shared decision making: what do clinicians need to know and why should they bother? Med $J$ Aust 2014;201:35-9.
24. Pham MT, Rajić A, Greig JD, et al. A scoping review of scoping reviews: advancing the approach and enhancing the consistency. Res Synth Methods 2014;5:371-85.

25. Levac D, Colquhoun H, O'Brien KK. Scoping studies: advancing the methodology. Implement Sci 2010;5:69.

26. National Health and Medical Research Council. NHMRC levels of evidence and grades for recommendations for developers of guidelines. Australian Government: NHMRC, 2009. http://www. nhmrc.gov.au/_files_nhmrc/file/guidelines/evidence_statement_form. pdf.

27. SA Health-Government of South Australia. About the elective surgery dashboard: SA Health, 2015. Available: http://www.sahealth.sa.gov. au/wps/wcm/connect/public+content/sa+health+internet/about+us/ our+performance/our+hospital+dashboards/about+the+elective+ surgery+dashboard (cited 20 Mar 2017).

28. StataCorp. Stata Statistical Software: Release 12. College Station, TX: StataCorp LP, 2011

29. Lin M-L, Pang M-CS, Chen C-H. Family as a whole: elective surgery patients' perception of the meaning of family involvement in decision making. J Clin Nurs 2013;22:271-8.

30. Lin ML, Huang CT, Chen CH. Reasons for family involvement in elective surgical decision-making in Taiwan: a qualitative study. J Clin Nurs 2017;26:1969-77

31. Lin ML, Chen $\mathrm{CH}$. Difficulties in surgical decision making and associated factors among elective surgical patients in Taiwan. $J$ Nurs Res 2017;25:1-470.

32. Wieser T, Steurer MP, Steurer M, et al. Factors influencing the level of patients using the internet to gather information before anaesthesia: a single-centre survey of 815 patients in Switzerland. BMC Anesthesiol 2017;17:39.

33. Arterburn $\mathrm{D}$, Wellman $\mathrm{R}$, Westbrook $\mathrm{E}$, et al. Introducing decision aids at Group Health was linked to sharply lower hip and knee surgery rates and costs. Health Aff 2012;31:2094-104.

34. Cornoiu A, Beischer AD, Donnan L, et al. Multimedia patient education to assist the informed consent process for knee arthroscopy. ANZ J Surg 2011;81:176-80.

35. Batuyong ED, Jowett AJ, Wickramasinghe $\mathrm{N}$, et al. Using multimedia to enhance the consent process for bunion correction surgery. ANZ $J$ Surg 2014;84:249-54.

36. Deyo RA. Commentary: Managing patients with back pain: putting money where our mouths are not. Spine $J$ 2011;11:633-5.

37. Hoppe DJ, Denkers M, Hoppe FM, et al. The use of video before arthroscopic shoulder surgery to enhance patient recall and satisfaction: a randomized-controlled study. J Shoulder Elbow Surg 2014:23:e134-e139.

38. Fraval A, Chandrananth J, Chong YM, et al. Internet based patient education improves informed consent for elective orthopaedic surgery: a randomized controlled trial. BMC Musculoskelet Disord 2015;16:14

39. Brunnekreef JJ, Schreurs BW. Total hip arthroplasty: what information do we offer patients on websites of hospitals? BMC Health Serv Res 2011;11:83.

40. Fraval $A$, Ming Chong $Y$, Holcdorf D, Plunkett $D$, et al. Internet use by orthopaedic outpatients - current trends and practices. Australas Med J 2012;5:633-8.

41. Johansson K, Salanterä S, Katajisto J. Empowering orthopaedic patients through preadmission education: results from a clinical study. Patient Educ Couns 2007;66:84-91.

42. Gooberman-Hill R, Sansom A, Sanders CM, et al. Unstated factors in orthopaedic decision-making: a qualitative study. BMC Musculoskelet Disord 2010;11:213.

43. Moser A, Korstiens I, van der Weijden T, et al. Themes affecting health-care consumers' choice of a hospital for elective surgery when receiving web-based comparative consumer information. Patient Educ Couns 2010;78:365-71.

44. Hawker GA, Wright JG, Coyte PC, et al. Determining the need for hip and knee arthroplasty: the role of clinical severity and patients' preferences. Med Care 2001;39:206-16.

45. Georgalas C, Ganesh K, Papesch E. The information and consent process in patients undergoing elective ENT surgery: a crosssectional survey. BMC Ear Nose Throat Disord 2008;8:5

46. Arterburn DE, Westbrook EO, Bogart TA, et al. Randomized trial of a video-based patient decision aid for bariatric surgery. Obesity 2011;19:1669-75.

47. Brown A, Furnham A, Glanville L, et al. Factors that affect the likelihood of undergoing cosmetic surgery. Aesthet Surg $J$ 2007;:27:501-8.

48. Parmeshwar N, Reid CM, Park AJ, et al. Evaluation of Information Sources in Plastic Surgery Decision-making. Cureus 2018;10:e2773. 
49. Swami V. Body appreciation, media influence, and weight status predict consideration of cosmetic surgery among female undergraduates. Body Image 2009;6:315-7.

50. Ihedioha U, Vaughan S, Mastermann J, et al. Patient education videos for elective colorectal surgery: results of a randomized controlled trial. Colorectal Dis 2013;15:1436-41.

51. O'Brien L, McKeough C, Abbasi R. Pre-surgery education for elective cardiac surgery patients: A survey from the patient's perspective. Aust Occup Ther J 2013;6:315-7.

52. Tamhankar AP, Mazari FA, Everitt NJ, et al. Use of the internet by patients undergoing elective hernia repair or cholecystectomy. Ann $R$ Coll Surg Engl 2009;91:460-3.

53. Smith F, Carlsson E, Kokkinakis D, et al. Readability, suitability and comprehensibility in patient education materials for Swedish patients with colorectal cancer undergoing elective surgery: a mixed method design. Patient Educ Couns 2014;94:202-9.

54. Ohlsson-Nevo E, Andershed B, Nilsson U, et al. Life is back to normal and yet not - partners' and patient's experiences of life of the first year after colorectal cancer surgery. J Clin Nurs 2012;21(34):555-63.

55. Noorian C, Aein F. Comparative investigation of the effectiveness of face-to-face verbal training and educational pamphlets on readiness of patients before undergoing non-emergency surgeries. J Educ Health Promot 2015;4:45.

56. Tongue J, Epps H, Forese L. Communication skills for patientcentered care. Research-based easily learned techniques for medical interviews that benefit orthopaedic surgeons and their patients. $J$ bone joint surg 2005;87:652-8.

57. Ha JF, Longnecker N. Doctor-patient communication: a review. Ochsner J 2010;10:38-43.

58. Ankuda CK, Block SD, Cooper Z, et al. Measuring critical deficits in shared decision making before elective surgery. Patient Educ Couns 2014;94:328-33.

59. Delinsky SS. Cosmetic surgery: a common and accepted form of self-improvement?. J App/ Soc Psychol 2005;35:2012-28.

60. Park LE, Calogero RM, Harwin MJ, et al. Predicting interest in cosmetic surgery: interactive effects of appearance-based rejection sensitivity and negative appearance comments. Body Image 2009;6:186-93.

61. Baker L, Wagner TH, Singer S, et al. Use of the Internet and e-mail for health care information: results from a national survey. JAMA 2003;289:2400-6.
62. Sansom A, Donovan J, Sanders C, et al. Routes to total joint replacement surgery: patients' and clinicians' perceptions of need. Arthritis Care Res 2010;62:1252-7.

63. Murray E, Pollack L, White M, et al. Clinical decision-making: Patients' preferences and experiences. Patient Educ Couns 2007;65:189-96.

64. Sheard C, Garrud P. Evaluation of generic patient information: effects on health outcomes, knowledge and satisfaction. Patient Educ Couns 2006;61:43-7.

65. Tassone P, Georgalas C, Patel NN, et al. Do otolaryngology outpatients use the internet prior to attending their appointment? $J$ Laryngol Otol 2004;118:34-8.

66. Brashers DE, Goldsmith DJ, Hsieh E. Information seeking and avoiding in health contexts. Hum Commun Res 2002;28:258-71.

67. Bundorf MK, Wagner TH, Singer SJ, et al. Who searches the internet for health information? Health Serv Res 2006;41:819-36.

68. Koch-Weser S, Bradshaw YS, Gualtieri L, et al. The Internet as a health information source: findings from the 2007 Health Information National Trends Survey and implications for health communication. J Health Commun 2010;15(sup3):279-93.

69. Australian Bureau of Statistics. Use of internet by householders, Australia, 2015;8153.0. Canberra: Australian Bureau of Statistics, 2015.

70. Wong $\mathrm{C}$, Harrison $\mathrm{C}$, Britt $\mathrm{H}$, et al. Patient use of the internet for health information. Australian Family Physician 2014;43:876-7.

71. Benigeri M, Pluye P. Shortcomings of health information on the Internet. Health Promot Int 2003;18:381-6.

72. Vance K, Howe W, Dellavalle RP. Social internet sites as a source of public health information. Dermatol Clin 2009;27:133-6.

73. Eysenbach $\mathrm{G}$. The impact of the Internet on cancer outcomes. $C A$ Cancer J Clin 2003:53:356-71.

74. Jayadev C, Khan T, Coulter A, et al. Patient decision aids in knee replacement surgery. Knee 2012;19:746-50.

75. Batuyong $E$, Birks $C$, Beischer AD. The use of multimedia as an adjunct to the informed consent process for ankle ligament reconstruction surgery. Foot Ankle Spec 2012;5:150-9.

76. Gogos AJ, Clark RB, Bismark MM, et al. When informed consent goes poorly: a descriptive study of medical negligence claims and patient complaints. Med J Aust 2011;195:340-4.

77. Mckeague M, Windsor J. Patients' perception of the adequacy of informed consent: a pilot study of elective general surgical patients in Auckland. NZ Med J 2003;116:U355. 